Journal of Mathematics and Statistics 2 (1): 343-345, 2006

ISSN 1549-3644

(C) 2005 Science Publications

\title{
Reduced Assumption in the Banach Contraction Principle
}

\author{
Sahar Mohamed Ali \\ Department of Mathematics, Faculty of Science, Ain Shams University, Cairo, Egypt
}

\begin{abstract}
In this study we introduce a novel class of normed spaces called weakly Cauchy normed spaces not necessarily complete in general and proved the existence of a fixed point of contraction mappings in these spaces, this is weaker assumption than the completeness assumption imposed on the given normed space on the other side the contraction condition valid only on a closed convex subset of the given space.
\end{abstract}

Key words: Reduced assumption, contraction mapping, Banach contraction principle, normed spaces

\section{INTRODUCTION}

Needless to say, fixed point theorem plays a major role in many applications, including variational and linear inequalities, optimization and applications in the field of approximation theory and minimum norm problems. Thus mathematical analysis of the fixed point theory drawn much attention in research.

We used the concept of weakly Cauchy normed spaces to prove the existence of the best approximation elements of a convex closed subsets in normed spaces not necessarily be reflexive Banach space or Hilbert space $^{[1]}$.

In this study we used the same concept of normed space to prove the existence of a fixed point of contraction mapping on such spaces in which reduced assumption is imposed. Thus we give the following definition.

Definition $^{[1]}$ :A normed space $X$ is said to be weakly Cauchy space if and only if every Cauchy sequence in $\mathrm{X}$ is weakly convergent to an element $\mathrm{X}$ in $\mathrm{X}$. A mapping $T$ on a normed space $X$ into $X$ is said to be contraction if and only if there is a non-negative real number $\mathrm{r}<1$ with the property that

$\|T(x)-T(y)\| \leq r\|x-y\|$ for every $x, y \in X$.

And is said to be nonexpansive if and only if

$\|T(x)-T(y)\| \leq\|x-y\|$ for every $x, y \in X$.

As $\mathrm{T}$ is contraction, it preserves strong convergence, but it does not preserve weak convergence in general.

The following is the Banach contraction principle which is the basis theorem of fixed point theory long time ago.

Theorem $^{[2]}$ :Let $\mathrm{X}$ be a complete metric space and let $\mathrm{T}$ be a contraction of $\mathrm{X}$ into itself. Then $\mathrm{T}$ has a unique fixed point in the sense that $T(x)=x$ for some $x \in X$.
Moreover, the sequence $\left\{\mathrm{T}^{\mathrm{n}}(\mathrm{y})\right\}_{\mathrm{n}} \in \mathrm{N}$ is strongly convergent to $\mathrm{x}$ for every $\mathrm{y} \in \mathrm{X}$.

Mathematician in the field of fixed point theory try to improve the results of this theorem in which changing the assumptions imposed on contraction mapping or on the given topological space, as the case of nonexpansive mappings while compact or Hilbert spaces are necessarily or as in the case of Caristi's fixed point theorem using a proper convex lower semi continuous mappings, for other many other trials one can see $\mathrm{Kirk}^{[3]}$.

Notations and Basic Definition: Let $X$ be a linear space. Then a function $\mathrm{f}$ from $\mathrm{X}$ into $(-\infty, \infty]$ is said to be proper lower semicontinuous and convex function if it satisfies the following conditions:

1. There is $x \in X$ such that $f(x)<\infty$ (proper).

2. For any real number $\alpha$, the set $\{x \in X: f(x) \leq \alpha\}$ is closed convex subset of $\mathrm{X}$ (lower semicontinuous).

3. For any $x, y \in X$ and $t \in[0,, 1], f(t x+(1-t) y) \leq t$ $\mathrm{f}(\mathrm{x})+(1-\mathrm{t}) \mathrm{f}(\mathrm{y})$ (convex function).

Remark:Notice that if $\mathrm{X}$ is a normed space and $\left\{x_{n}\right\}_{n} \in N$ is weakly Cauchy sequence in $X$ (in the sense that $\left\{\mathrm{f}\left(\mathrm{x}_{\mathrm{n}}\right)\right\}_{\mathrm{n}} \in \mathrm{N}_{\mathrm{N}}$ is Cauchy for every linear bounded functional $f$ in $\left.X^{*}\right)$ which has a subsequence $\left\{x_{n i}\right\}_{i} \in N$ convergent weakly to an element $\mathrm{x}$ in $\mathrm{X}$, then the sequence $\left\{\mathrm{x}_{\mathrm{n}}\right\}_{\mathrm{n}} \in \mathrm{N}$ is weakly convergent to the same weak limit.

We have the following lemmas:

Lemma1:Let $X$ be a weakly normed Cauchy space and $\left\{\mathrm{C}_{\mathrm{n}}\right\}_{\mathrm{n}} \in \mathrm{N}_{\mathrm{N}}$ be a descending sequence of closed bounded convex subsets of $X$ such that $-\lim _{n \rightarrow \infty} \operatorname{Diam}\left(C_{n}\right)=0$. Then the intersection $\bigcap_{n=1}^{\infty} C_{n} \neq \Phi$ is not empty.

Corresponding Author: Sahar Mohamed Ali, Department of Mathematics, Faculty of Science, Ain Shams University, Cairo, Egypt 
Lemma2:Every reflexive normed space is weakly Cauchy

space.

Proof: It is required to show that every Cauchy sequence in a reflexive normed space $\mathrm{X}$ is weakly convergent. So, let $\left\{\mathrm{x}_{\mathrm{n}}\right\}_{\mathrm{n}} \in \mathrm{N}_{\mathrm{N}}$ be a Cauchy sequence in $X$. Since

$\left\|f\left(x_{n}-x_{m}\right)\right\| \leq\|f\|\left\|x_{n}-x_{m}\right\|$ for every $f \in X^{*}$,

$\left\{f\left(x_{n}\right)\right\}_{n} \in{ }_{N}$ is Cauchy sequence of numbers for every linear bounded functional $\mathrm{f}$ on $\mathrm{X}$, hence it is convergent, let $\lim _{n \rightarrow \infty} f\left(x_{n}\right)=\alpha_{f}$ and define the linear bounded functional $F$ on $X^{*}$ by $F(f)=\alpha_{f}$, since $X$ is reflexive, there is $x$ in $X$ such that $F(f)=f(x)$ for every $f$ $\in \mathrm{X}^{*}$, this proved that $\left\{\mathrm{f}\left(\mathrm{x}_{\mathrm{n}}\right)\right\}_{\mathrm{n}} \in \mathrm{N}$ is convergent to $f(x)$ for some $x$ in $X$ and for every $f \in X^{*}$, hence $x$ is the required weak limit.

The following is the main Theorem:

Theorem 1: Let $X$ be a weakly Cauchy normed space, $\mathrm{C}$ be a closed convex subset of $\mathrm{X}$ and $\mathrm{T}$ a contraction mapping from $\mathrm{C}$ into $\mathrm{C}$. Then $\mathrm{T}$ has a unique fixed point $\mathrm{y} \in \mathrm{C}$. Moreover $\left\{\mathrm{T}^{\mathrm{n}}(\mathrm{x})\right\}_{\mathrm{n}} \in \mathrm{N}_{\mathrm{N}}$ is weakly convergent to $\mathrm{y}$ for every $\mathrm{x} \in \mathrm{C}$, $\mathrm{w}-\lim _{\mathrm{n} \rightarrow \infty} \mathrm{T}^{\mathrm{n}}(\mathrm{x})=\mathrm{y}$ for every $\mathrm{x} \in \mathrm{C}$.

Proof: Let $\mathrm{x}$ in $\mathrm{X}$, since $\mathrm{T}$ is contraction, the inequalities

$\left\|T^{n+1}(x)-T^{n}(x)\right\| \leq r^{n}\|T(x)-x\|$,

insures that, if $1 \leq \mathrm{m}$, we have,

$\left\|T^{\mathrm{m}}(\mathrm{x})-\mathrm{T}^{\mathrm{l}}(\mathrm{x})\right\| \leq\left(\mathrm{r}^{\mathrm{l}} / 1-\mathrm{r}\right)\|\mathrm{T}(\mathrm{x})-\mathrm{x}\|$,

and in turns shows that, the sequence $\left\{\mathrm{T}^{\mathrm{n}}(\mathrm{x})\right\}_{\mathrm{n}} \in \in_{\mathrm{N}}$ is Cauchy sequence in $\mathrm{X}$, since $\mathrm{X}$ is weakly Cauchy, the Cauchy sequence $\left\{T^{n}(x)\right\}_{n} \in{ }_{N}$ is weakly convergent to some element $\mathrm{y} \in \mathrm{X}$, since $\mathrm{C}$ is convex closed, it contains all its weak limits as well as all its strong limits, hence $\mathrm{y}$ in $\mathrm{C}$, we claim that $\mathrm{y}$ is the unique fixed point of $\mathrm{T}$, to prove that, let 1 be any arbitrarily natural number and define the proper lower-semicontinuous convex real valued function $\mu_{1}$ on $\mathrm{C}$ by the following formula: $\mu_{1}(\mathrm{x})=\left\|\mathrm{T}^{\mathrm{l}}(\mathrm{y})-\mathrm{x}\right\|$

for any real number $\alpha$, the set $G_{1 \alpha}:=\left\{x \in C: \mu_{1}(x) \leq \alpha\right.$ \} is closed convex subset of $\mathrm{C}$ and in particular, for any $\mathcal{E}>0$ the set

$\mathrm{G}_{\{\|\mathrm{T}(\mathrm{y})-\mathrm{y}\|} \mathcal{E}_{\}}:=\left\{\mathrm{x} \in \mathrm{C}:\left\|\mathrm{T}^{\mathrm{l}}(\mathrm{y})-\mathrm{x}\right\| \leq\left\|\mathrm{T}^{\mathrm{l}}(\mathrm{y})-\mathrm{y}\right\|-\mathcal{E}\right\}$

is closed convex, hence it is closed in the weak topology, therefore its complement

$\left.\mathrm{G}_{\{\| \mathrm{C} 1(\mathrm{y}) \text {-y\|- }}^{\mathrm{c}}\right\}:=\left\{\mathrm{x} \in \mathrm{C}:\left\|\mathrm{T}^{\mathrm{l}}(\mathrm{y})-\mathrm{x}\right\|>\left\|\mathrm{T}^{\mathrm{l}}(\mathrm{y})-\mathrm{y}\right\|-\mathcal{E}\right\}$

is weakly open set which containing y, then there is a neighborhood $\mathrm{N}(\mathrm{y})$ of $\mathrm{y}$ such that $\mathrm{N}(\mathrm{y}) \subset \mathrm{G}^{\mathrm{c}}{ }_{\text {i|TT(y)-y\|- }}$ $\mathcal{E}_{\text {, }}$, on the other side, using the fact that $\mathrm{y}$ is the weak limit point of $\left\{T^{\mathrm{n}}(\mathrm{x})\right\}_{\mathrm{n}} \in \mathrm{N}$, there is $\mathrm{n}_{0} \in \mathrm{N}$ such that $\mathrm{T}^{\mathrm{n}}$ $(x) \in N(y)$ for every $n \geq n_{0}$, it follows that,

$\left\|\mathrm{T}^{\mathrm{l}}(\mathrm{y})-\mathrm{y}\right\|-\varepsilon<\left\|\mathrm{T}^{\mathrm{l}}(\mathrm{y})-\mathrm{T}^{\mathrm{n}}(\mathrm{x})\right\|$ for every $\mathrm{n} \geq \mathrm{n}_{0}$.

We have two cases, the first is when $\mathrm{n}_{0} \leq 1$, for such a

case, one has

$\left\|\mathrm{T}^{\mathrm{l}}(\mathrm{y})-\mathrm{y}\right\|-\varepsilon<\left\|\mathrm{T}^{\mathrm{l}}(\mathrm{y})-\mathrm{T}^{\mathrm{l}}(\mathrm{x})\right\|$,

which in turns showed that,

$\left\|\mathrm{T}^{\mathrm{l}}(\mathrm{y})-\mathrm{y}\right\|-\varepsilon<\left\|\mathrm{T}^{\mathrm{l}}(\mathrm{y})-\mathrm{T}^{\mathrm{l}}(\mathrm{x})\right\| \leq \mathrm{r}^{\mathrm{l}}\|\mathrm{y}-\mathrm{x}\|$,

The other case, if $1<\mathrm{n}_{0}$, for that we have the following inequality

$\left\|\mathrm{T}^{\mathrm{l}}(\mathrm{y})-\mathrm{T}^{\mathrm{n}}(\mathrm{x})\right\| \leq \mathrm{r}^{\mathrm{l}}\{(\mathrm{r} / 1-\mathrm{r})\|\mathrm{T}(\mathrm{x})-\mathrm{x}\|+\|y-\mathrm{x}\|\}$,

In both cases, taking the limit as 1 tends to infinity, we see that

$0 \leq \lim _{1 \rightarrow \infty}\left\|\mathrm{T}^{\mathrm{l}}(\mathrm{y})-\mathrm{y}\right\|<\varepsilon$

Since $\varepsilon$ is arbitrarily, one get

$\lim _{1 \rightarrow \infty}\left\|\mathrm{T}^{\mathrm{l}}(\mathrm{y})-\mathrm{y}\right\|=0$,

thus the sequence $\left\{\mathrm{T}^{\mathrm{n}}(\mathrm{y})\right\}_{\mathrm{n}} \in_{\mathrm{N}}$ converges strongly to $\mathrm{y}$, since $\mathrm{T}$ preserves strong convergence, we have

$\mathrm{T}(\mathrm{y})=\mathrm{T}\left(\lim _{\mathrm{l} \rightarrow \infty} \quad \mathrm{T}^{\mathrm{n}}(\mathrm{y})\right)=\quad \lim _{\mathrm{l} \rightarrow \infty} \quad \mathrm{T}\left(\mathrm{T}^{\mathrm{n}}(\mathrm{y})\right)=$ $\lim _{1 \rightarrow \infty} T^{\mathrm{n}+1}(\mathrm{y})=\mathrm{y}$.

This shows that $\mathrm{y}$ is a fixed point of $\mathrm{T}$, to show that $\mathrm{y}$ is unique, let $\mathrm{z}$ be another fixed point, we have the following contradiction,

$\|y-z\|=\|T(y)-T(z)\| \leq r$ $\|y-z\|<\|y-z\|$.

This ends the proof.

We have the following corollaries:

Corollary1:Let $\mathrm{X}$ be a reflexive normed space, $\mathrm{C}$ be a closed convex subset of $\mathrm{X}$ and $\mathrm{T}$ contraction mapping from $\mathrm{C}$ into itself. Then $\mathrm{T}$ has a unique fixed point $\mathrm{y}$ in C. Moreover

$\mathrm{W}-\lim _{1 \rightarrow \infty} \mathrm{T}^{\mathrm{n}}(\mathrm{x})=\mathrm{y}$ for every $\mathrm{x} \in \mathrm{C}$.

Proof: Using Theorem (1) and lemma (2), we get the proof.

Corollary2:Let $\mathrm{X}$ be a weakly Cauchy normed space and $\mathrm{T}$ be a contraction mapping on $\mathrm{X}$ into itself, if $\mathrm{G}$ is the class of all closed convex subsets of $\mathrm{X}$ which invariant under $\mathrm{T}$. Then the intersection $\bigcap_{C \in G} C \neq \Phi$ is not empty.

Proof: Using Theorem (1), the intersection is a set containing at least the unique fixed point of $\mathrm{T}$.

Remarks: Using the generalization of Caristi's fixed point theorem and the characterization of complete metric space introduced by Wataru ${ }^{[4]}$, Theorem (1) insures that the class of weakly contractive mappings on Banach spaces is containing properly the class of all contraction mappings. 


\section{REFERENCES}

1. El-Shobaky, E. M., Sahar Mohammed Ali and Wataru Takahashi, 2001. On The Projection Constant Problems And The Existence Of The Metric Projections in normed spaces. Abstr. Appl. Anal. 6 :no.7: 401-410.

2. Mohamed, A. K and W. A. Kirk, 2001. An Introduction to Metric Spaces and Fixed Point Theory", A Wiley-Interscience Publication. John Wiley and Sons, Inc. New York.
3. Kirk, W. A. and B. Sims, 2001. Handbook of Metric Fixed Point Theory. Kluwer Academic Publishers. Dordrecht. Boston. London.

4. Wataru, T.2000. Nonlinear Functional Analysis, Fixed Point Theory and its Applications. Yokohama Publishers, Yokohama. 